\title{
DIAGNÓSTICO EMPRESARIAL DE LA CIUDAD DE IPIALES: UNA APROXIMACIÓN A PARTIR DEL CENSO ECONÓMICO - EMPRESARIAL*
}

\author{
Por: Víctor David Jaramillo Mejía ${ }^{1}$
}

\begin{abstract}
RESUMEN
Este artículo presenta un resumen frente al censo empresarial, proyecto financiado por la Cámara de Comercio de Ipiales, en convenio con Comfamiliar, SENA-Ipiales, y que fue terminado en el mes de diciembre del año 2011. En general, el estudio busca describir el sector empresarial de la ciudad de Ipiales, realizar una caracterización de sus problemáticas y analizar la informalidad, como una traba en el desarrollo económico y social del municipio de Ipiales. Para ello se realizó un análisis sectorial y por estratos, que apoyado en Cartografía, y análisis econométricos permitieron georeferenciar las unidades productivas de la ciudad, determinar las zonas de mayor concentración de las empresas e identificar las dinámicas de mercado en la ciudad de Ipiales. Finalmente, se contemplan algunas conclusiones de solución a algunas problemáticas.
\end{abstract}

Palabras claves: Unidad productiva, formalización, informalidad.

Clasificación JEL: D24, L11, M21.

1. Economista de la Universidad de Nariño, Máster en Dirección de Proyectos de la Universidad de Valladolid. Docente Universitario. Consultor Censo económico y empresarial de Ipiales, 2011 Investigador adscrito al Centro de Estudios de Desarrollo Regional y Empresarial (CEDRE) de la Universidad de Nariño. mailto: victorjaramillo48@hotmail.com

* Agradecimientos a la Cámara de Comercio de Ipiales por posibilitar el desarrollo de esta investigación. Y un especial reconocimiento al Ec. Jhon Jairo Suárez y la Ing. Elisabeth Rojas, supervisores de campo, los coordinadores de campo: Omar Eduardo Benavides, Andrea Marisol Cabrera, Lizeth Calderón Campaña, Edwin Andrés Chamorro, Jhon Gerardo Charfuelán, Jhon Wilmar Mora, y los 74 encuestadores, aprendices del Centro Sur Colombiano de Logística Internacional -SENA Regional Nariño- que posibilitaron el desarrollo de este trabajo.

Fecha de recepción: 6 de octubre de 2013 - Fecha de aprobación definitiva: 15 de febrero de 2014. 
BUSINESS DIAGNOSIS OF THE IPIALES CITY: AN APPROACH FROM

\author{
By: Víctor David Jaramillo Mejía
}

\begin{abstract}
This article presents a summary of the business census, a project funded by the Cámara de comercio de Ipiales, realized with Comfamiliar, SENA-Ipiales, it was completed in December 2011. Generally the study aims to describe the business sector of I piales city, to characterize their problems, and analyze the informality as an obstacle on the economic and social development of Ipiales. This was analyzed by sector and stratum, which supported by cartography and econometric analysis allowed the production units of the city, establish the areas with more companies and identify market dynamics in Ipiales City. Finally, some conclusions are provided to solve some problems.
\end{abstract}

Key words: Production unit, formalization, informality.

JEL Classification: D24, L11, M21. 
La economía moderna es dirigida. O la dirige el Estado o la dirigen los poderes económicos. Estamos en un mundo económicamente organizado por medidas políticas, y el que no organiza su economía políticamente es una víctima. El cuento de la división internacional del trabajo, con el de la libertad de comercio, que es su ejecución, es pues una de las tantas formulaciones doctrinarias, destinadas a impedir que organicemos sobre los hechos nuestra propia doctrina económica.

Arturo Jauretche

\section{INTRODUCCIÓN}

Ipiales, como uno de los principales puentes fronterizos de Colombia, está expuesta a grandes problemas de tipo cambiario y comercial; de aquí que muchos de los empresarios de la ciudad tengan un alto grado de dependencia de la dualidad comercial fronteriza lo que provoca pérdidas económicas, en tiempos de apreciación cambiaria, o ganancia en épocas de devaluación (Cámara de Comercio de Ipiales; CIESI Consultores, 2012).

Este artículo sintetiza el estudio de Censo Empresarial de la ciudad de Ipiales, el cual busca dimensionar la problemática empresarial, demostrando que el bajo desarrollo de las unidades productivas, la dependencia del sector terciario y la alta informalidad empresarial, han generado la existencia de problemas económicos estructurales, que finalmente derivan en el bajo progreso de la ciudad.

La investigación fue financiada por Cámara de Comercio de Ipiales, en convenio con Comfamiliar y el SENA - Ipiales, y desde sus inicios pretendió generar un estudio de línea base que permita la toma de política pública o privada, en favor del desarrollo de la ciudad fronteriza.

\section{UBICACIÓN ESPACIAL DE LAS EMPRESAS}

Esta investigación intentó cubrir toda la zona urbana del municipio de Ipiales (ver mapa No. 1), dividido en ocho sectores delimitados según cartografía. Para tener una cobertura total del sector urbano, el censo también llegó a los sectores de San Luis, Las Lajas, San Juan, y la vía a Rumichaca catalogadas como zonas periféricas, pero representativas para el estudio por ser paso obligado de viajeros que transitan por la frontera.

Esta división permitió desarrollar una metodología eficiente de estudio, que contribuyó a identificar en la zona urbana de Ipiales 5.273 unidades productivas (UP), de las cuales se obtuvo el total de la información en el 84\% de los casos, mientras que el $16 \%$ no quisieron responder por temor a presiones policivas e impositivas (Tabla No. 1). Por ese motivo, a pesar de conocer el número total de las empresas se decidió tomar como marco muestral, el número de UP que respondieron los cuestionarios. 


\section{Mapa No. 1.}

LOCALIZACIÓN DE LAS UNIDADES PRODUCTIVAS EN LA CIUDAD DE IPIALES

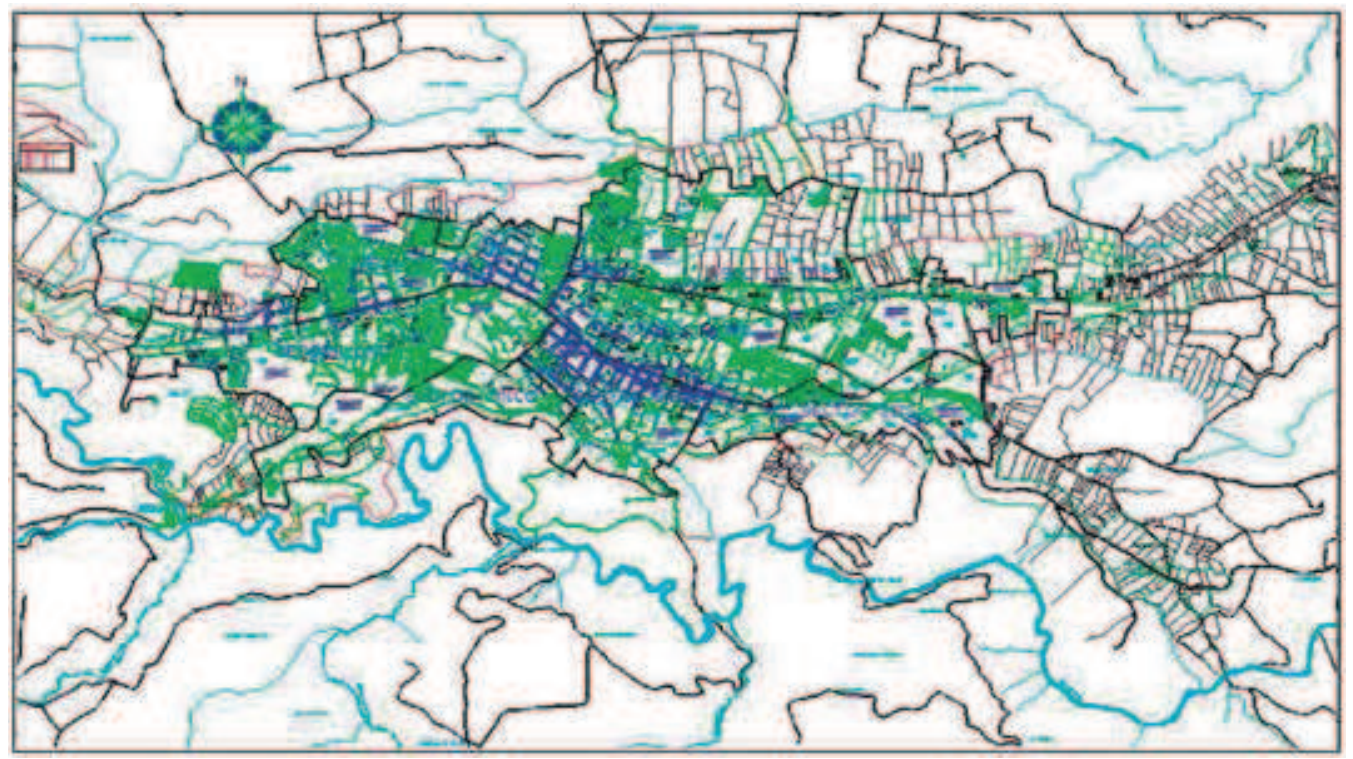

Fuente: Construcción propia a partir de los datos de campo y la plantilla de IGAC.

Tabla No. 1.

\section{COBERTURA DEL CENSO}

\begin{tabular}{lcc}
\hline \multicolumn{1}{c}{ Concepto } & Cantidad & Porcentaje \\
\hline UP Ubicadas & 5273 & $100 \%$ \\
UP Censadas & 4431 & $84 \%$ \\
UP Rechazadas & 842 & $16 \%$ \\
\hline
\end{tabular}

Fuente: Trabajo de campo realizado a los comerciantes con emplazamiento fijo de la ciudad de Ipiales.

Asimismo, el estudio permitió encontrar que el sector con mayor número de UP es el siete (7) con 1.767 establecimientos (33,51\%), seguido del sector cuatro (4) con 1.210 UP $(22,95 \%)$, cabe señalar que estos dos sectores se encuentran ubicados en el centro de la ciudad, en las zonas más comerciales del municipio, las cuales están ubicadas entre la carrera $5^{\mathrm{a}}, 6^{\mathrm{a}}$ y $7^{\mathrm{a}}$ entre calles 17 y $4^{\mathrm{a}}$; en tercer lugar se encuentra el sector dos (2) con el 14,07\% de empresas, los sectores cinco (5) y ocho (8) reportaron 118 y 17 establecimientos respectivamente, los cuales corresponden a los sectores con menos establecimientos censados ya que se encuentran lejanos al centro de la ciudad (Tabla No. 2). 
Tabla No. 2.

UNIDADES PRODUCTIVAS CENSADAS POR SECTOR

\begin{tabular}{ccc}
\hline Cód. Sector & Cantidad & \multicolumn{1}{l}{ Porcentaje } \\
\hline 1 & 552 & $10,5 \%$ \\
2 & 742 & $14,1 \%$ \\
3 & 657 & $12,5 \%$ \\
4 & 1210 & $23,0 \%$ \\
5 & 118 & $2,2 \%$ \\
6 & 210 & $4,0 \%$ \\
7 & 1767 & $33,5 \%$ \\
8 & 17 & $0,3 \%$ \\
\hline Total general & $\mathbf{5 2 7 3}$ & $\mathbf{1 0 0} \%$ \\
\hline
\end{tabular}

Fuente: Trabajo de campo realizado a los comerciantes con emplazamiento fijo de la ciudad de Ipiales.

Con respecto al estrato socioeconómico en donde se encuentran ubicadas las unidades productivas, el censo identificó que la mayoría de ellas se concentran en los estratos 3 y 2 (gráfico No. 1). Este escenario tiene dos razones fundamentales: En primer lugar, los empresarios prefieren concentrarse en las zonas tradicionalmente comerciales, es decir, en la zona céntrica de la ciudad, la cual territorialmente a sido catalogada como estrato 3; Sin embargo, la segunda razón argumenta que ha sido tanta la concentración del comercio en esta zona, que las dinámicas de mercado han ido expandiendo el desarrollo de estas actividades hacia sectores aledaños, muchos de ellos atraídos por la reglamentación del uso del suelo, de ese modo los estratos 2 y 4 están creciendo.

Así, la mayor concentración de unidades productivas en el Municipio de Ipiales está en el sector siete (7) ya que cuenta con 698 empresas en el estrato 3, en este sector se encuentran la mayoría de los establecimientos formales, y por ende el perfil del usuario y el estrato donde están ubicados establecen la oferta, es decir, que las unidades productivas que se encuentran en este sector y en este estrato se preocupan más por el volumen de sus ventas, crecimiento empresarial y posicionamiento de sus negocios; contrario a los empresarios que se encuentran en estratos bajos y en sectores lejanos que se interesan menos por el crecimiento de sus negocios, por lo cual, en su mayoría, se encuentran como informales con establecimientos de subsistencia (Tabla No. 3). 
Gráfico No. 1.

UNIDADES PRODUCTIVAS SEGÚN EL ESTRATO SOCIOECONÓMICO

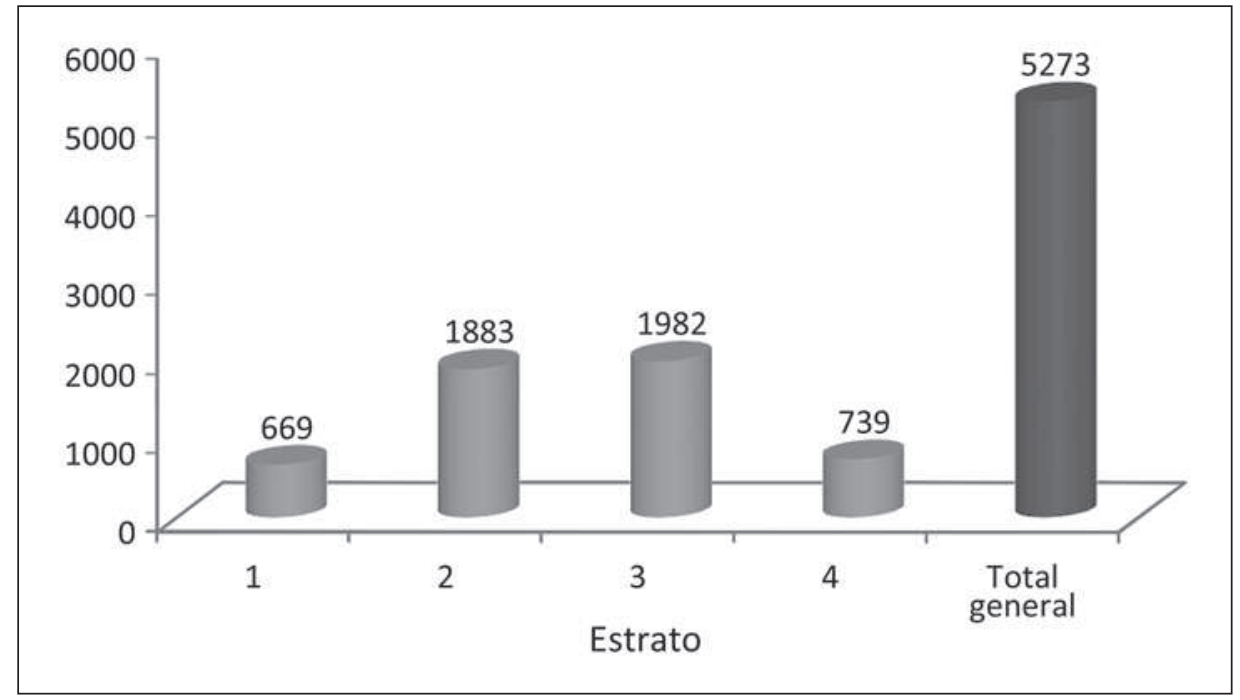

Fuente: Trabajo de campo realizado a los comerciantes con emplazamiento fijo de la ciudad de Ipiales.

Tabla No. 3.

ACTIVIDAD ECONÓMICA SEGÚN UNIDADES PRODUCTIVAS POR SECTOR

\begin{tabular}{cccccccccc}
\hline & \multicolumn{10}{c}{ SECTOR } \\
\hline ESTRATO & $\mathbf{1}$ & $\mathbf{2}$ & $\mathbf{3}$ & $\mathbf{4}$ & $\mathbf{5}$ & $\mathbf{6}$ & $\mathbf{7}$ & $\mathbf{8}$ & $\begin{array}{c}\text { TOTAL } \\
\text { GENERAL }\end{array}$ \\
& 89 & 61 & 135 & 172 & 35 & 28 & 139 & 10 & 669 \\
2 & 368 & 253 & 328 & 299 & 48 & 135 & 445 & 7 & 1883 \\
3 & 76 & 364 & 187 & 578 & 35 & 44 & 698 & - & 1982 \\
4 & 19 & 64 & 7 & 161 & - & 3 & 485 & - & 739 \\
\hline TOTAL GENERAL & 552 & $\mathbf{7 4 2}$ & $\mathbf{6 5 7}$ & $\mathbf{1 2 1 0}$ & $\mathbf{1 1 8}$ & $\mathbf{2 1 0}$ & $\mathbf{1 7 6 7}$ & $\mathbf{1 7}$ & $\mathbf{5 2 7 3}$ \\
\hline
\end{tabular}

Fuente: Trabajo de campo realizado a los comerciantes con emplazamiento fijo de la ciudad de Ipiales.

\section{DIAGNÓSTICO EMPRESARIAL DE LA CIUDAD DE IPIALES}

Como se contempló en la primera parte de este artículo, el 16\% de las empresas identificadas en la ciudad de Ipiales rechazaron contestar el cuestionario del censo empresarial, dejando como base estadística las 4.431 unidades productivas que respondieron la encuesta. 


\subsection{Estado Actual}

El 94,45\% de las empresas se encuentran en estado activo, es decir, no piensan cerrar su negocio o acabar con él, puesto que les generan ingresos tanto para el propietario como para los empleados. Sin embargo, el 5,55\% restante son UP que se encuentran inactivas o en liquidación, según los propietarios de estos establecimientos, sus negocios están desapareciendo por factores como la competencia desleal, la inseguridad, falta de crédito, entre otros (Gráfico No. 2).

Gráfico No. 2.

\section{ESTADO ACTUAL DE LAS UNIDADES PRODUCTIVAS}

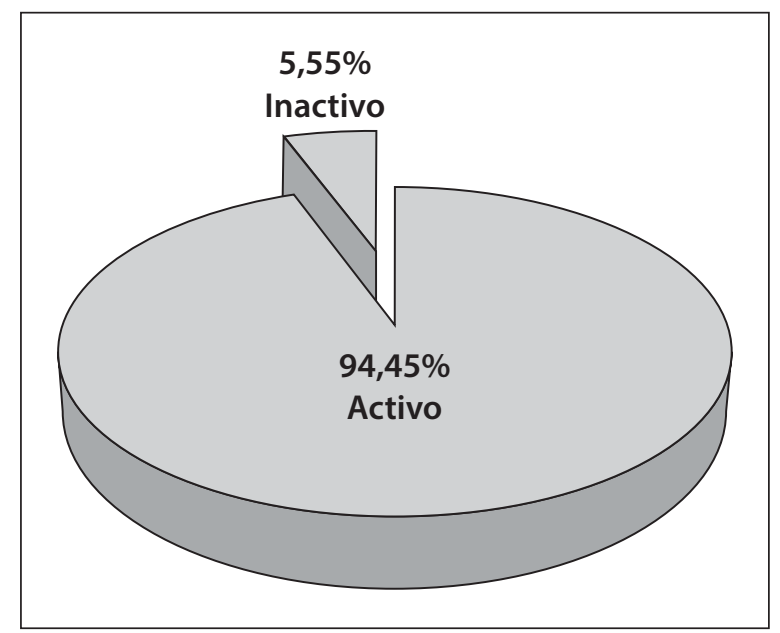

Fuente: Trabajo de campo realizado a los comerciantes con emplazamiento fijo de la ciudad de Ipiales.

\subsection{Tipo de Emplazamiento}

Respecto al lugar donde operan o funcionan las empresas del municipio se encontró que el 55,27\%, se ubican en locales u oficinas, por lo general este tipo de emplazamiento exige a los empresarios pagar los gastos de arrendamiento y administración de los locales comerciales; a este emplazamiento le sigue la vivienda con actividad económica (31,39\%). Es importante aclararle al lector el hecho que exista un número muy pequeño de empresas que se encuentran en emplazamiento tipo fábrica $(0,6 \%)$, este porcentaje revela una de las problemáticas más importantes de la ciudad fronteriza, que refiere a la baja existencia de organizaciones que tengan como actividad económica la creación o generación de valor agregado en las mercancías, dejando la hipótesis de una gran dependencia fronteriza con respecto a la dualidad del mercado comercial (Tabla No. 4). 
Tabla No. 4.

TIPO DE EMPLAZAMIENTO DE LA UNIDAD PRODUCTIVA

\begin{tabular}{|c|c|c|}
\hline EMPLAZAMIENTO & CANTIDAD & PORCENTAJE \\
\hline Local u Oficina & 2449 & $55,3 \%$ \\
\hline Vivienda con actividad económica & 1391 & $31,4 \%$ \\
\hline Puesto Fijo & 368 & $8,3 \%$ \\
\hline Fábrica & 27 & $0,6 \%$ \\
\hline No informa & 196 & $4,4 \%$ \\
\hline TOTAL GENERAL & 4431 & $100 \%$ \\
\hline
\end{tabular}

Fuente: Trabajo de campo realizado a los comerciantes con emplazamiento fijo de la ciudad de Ipiales.

\subsection{Tenencia de Matricula Mercantil}

Del total de unidades productivas censadas, 2.025 reportaron tener matrícula mercantil y este dato permite inferir que el $45,7 \%$ son establecientes formales con registros sobre la antigüedad de sus negocios. Por otro lado, el 54,3\% reportó no tener registro mercantil, deduciendo que 2.406 establecimientos son informales; entre las principales razones para no poseer este documento se encuentran: 1 . la falta de utilidad del mismo; 2. desconocimiento de la existencia de este requisito; 3. un gran número de negocios mencionan el reciente funcionamiento de la unidad productiva, razón por la cual aún no han realizado el tramite respectivo (Tabla No 5).

Tabla No. 5.

TENENCIA DE MATRÍCULA MERCANTIL

\begin{tabular}{ccc}
\hline & NÚMERO & PORCENTAJE \\
\hline No Tiene Registro Mercantil & 2406 & $54,3 \%$ \\
Tiene Registro Mercantil & 2025 & $45,7 \%$ \\
TOTAL & $\mathbf{4 4 3 1}$ & $\mathbf{1 0 0 \%}$ \\
\hline
\end{tabular}

Fuente: Trabajo de campo realizado a los comerciantes con emplazamiento fijo de la ciudad de Ipiales.

\subsection{Actividad Económica}

Frente a los grandes sectores de actividad económica se pueden resaltar: 1 . El comercio al por mayor y al por menor; reparación de vehículos automotores y motocicletas (50,28\%); 2. Las industrias manufactureras (9,12\%); 3. El sector de 
Información y comunicaciones (8,17\%); y 4. Las actividades de alojamiento y de servicio de comidas $(8,01 \%)$; entre ellas su participación equivale a 75,58\% sobre el total de las UP, lo que revela su importancia para la economía de esta ciudad (Ver tabla No. 6). Se destaca que el principal sector de actividad económica de Ipiales depende básicamente de la existencia de un gran número de pequeñas tiendas, restaurantes, venta de ropa y calzado, venta de frutas, venta de electrodomésticos, entre otros productos. Se debe resaltar que las actividades de Agricultura, Ganadería, Silvicultura y Pesca, Explotación de Minas y Canteras, no son representativos en la zona urbana del municipio, razón que evidencia la marginalidad de ellas con respecto a otros sectores económicos dentro de este estudio (Tabla No. 6).

Tabla No. 6.

\section{UNIDADES PRODUCTIVAS POR GRANDES SECTORES DE ACTIVIDAD ECONÓMICA}

\begin{tabular}{|c|c|c|c|}
\hline & SECTORES & $\mathrm{N}^{\circ}$ & $\%$ \\
\hline A & Agricultura, ganadería, silvicultura y pesca & 2 & $0,05 \%$ \\
\hline B & Explotación de minas y canteras & 1 & $0,02 \%$ \\
\hline C & Industrias manufactureras & 404 & $9,12 \%$ \\
\hline D & Suministro de electricidad, gas, vapor y aire acondicionado & 6 & $0,14 \%$ \\
\hline $\mathrm{E}$ & $\begin{array}{l}\text { Suministro de agua; evacuación de aguas residuales, gestión de } \\
\text { desechos y descontaminación }\end{array}$ & 3 & $0,07 \%$ \\
\hline $\mathrm{F}$ & Construcción & 18 & $0,41 \%$ \\
\hline G & $\begin{array}{l}\text { Comercio al por mayor y al por menor; reparación de vehículos } \\
\text { automotores y motocicletas }\end{array}$ & 2228 & $50,28 \%$ \\
\hline $\mathrm{H}$ & Transporte y almacenamiento & 206 & $4,65 \%$ \\
\hline I & Actividades de alojamiento y de servicio de comidas & 355 & $8,01 \%$ \\
\hline J & Información y comunicaciones & 362 & $8,17 \%$ \\
\hline K & Actividades financieras y de seguros & 179 & $4,04 \%$ \\
\hline L & Actividades inmobiliarias & 15 & $0,34 \%$ \\
\hline M & Actividades profesionales, científicas y técnicas & 120 & $2,71 \%$ \\
\hline $\mathrm{N}$ & Actividades de servicios administrativos y de apoyo & 37 & $0,84 \%$ \\
\hline $\mathrm{O}$ & $\begin{array}{l}\text { Administración pública y defensa; planes de seguridad social de } \\
\text { afiliación obligatoria }\end{array}$ & 12 & $0,27 \%$ \\
\hline$P$ & Enseñanza & 53 & $1,20 \%$ \\
\hline Q & Actividades de atención de la salud humana y de asistencia social & 88 & $1,99 \%$ \\
\hline $\mathrm{R}$ & Actividades artísticas, de entretenimiento y recreativas & 39 & $0,88 \%$ \\
\hline $\mathrm{S}$ & Otras actividades de servicios & 295 & $6,66 \%$ \\
\hline & $\begin{array}{l}\text { Actividades de los hogares como empleadores; actividades no di- } \\
\text { ferenciadas de los hogares como productores de bienes y servicios } \\
\text { para uso propio }\end{array}$ & 8 & $0,18 \%$ \\
\hline \multicolumn{2}{|r|}{ TOTAL GENERAL } & 4431 & $100 \%$ \\
\hline
\end{tabular}

Fuente: Trabajo de campo realizado a los comerciantes con emplazamiento fijo de la ciudad de Ipiales. 
La rama de industria manufacturera se caracteriza por empresas cuya transformación se realiza de forma artesanal, aquí sobresalen las ebanisterías, talabarterías, y algunas empresas del sector alimentos. Por su parte, el sector de información y telecomunicaciones se destaca por la existencia de un alto número de UP dedicadas a la venta de minutos (SAI o telemec) donde en su mayoría son negocios informales, no por ello aseverando que son establecimientos cuyo margen de ganancia es bajo.

Tabla No. 7.

UNIDADES PRODUCTIVAS POR ACTIVIDAD ECONÓMICA Y TAMAÑO DE LA EMPRESA

\begin{tabular}{|c|c|c|c|c|c|c|}
\hline CÓD.CIIU & ACTIVIDAD & $\begin{array}{l}\text { MICRO } \\
\text { EMPRESA }\end{array}$ & $\begin{array}{l}\text { PEQUEÑA } \\
\text { EMPRESA }\end{array}$ & $\begin{array}{l}\text { MEDIANA } \\
\text { EMPRESA }\end{array}$ & $\begin{array}{l}\text { GRAN } \\
\text { EMPRESA }\end{array}$ & TOTAL \\
\hline G4711 & $\begin{array}{l}\text { Venta al por menor en comercios no } \\
\text { especializados con predominio de la } \\
\text { venta de alimentos, bebidas o tabaco }\end{array}$ & 821 & 71 & 2 & 10 & 904 \\
\hline G4771 & $\begin{array}{l}\text { Venta al por menor de prendas de } \\
\text { vestir, calzado y artículos de cuero en } \\
\text { comercios especializados }\end{array}$ & 191 & 51 & 11 & 5 & 258 \\
\hline 15610 & $\begin{array}{l}\text { Actividades de restaurantes y de ser- } \\
\text { vicio móvil de comidas }\end{array}$ & 202 & 44 & 6 & 1 & 253 \\
\hline G4721 & $\begin{array}{l}\text { Venta al por menor de alimentos en } \\
\text { comercios especializados }\end{array}$ & 153 & 16 & 3 & 0 & 172 \\
\hline J6110 & $\begin{array}{l}\text { Actividades de telecomunicaciones } \\
\text { alámbricas }\end{array}$ & 134 & 24 & 2 & 5 & 165 \\
\hline G4520 & $\begin{array}{l}\text { Mantenimiento y reparación de vehí- } \\
\text { culos automotores }\end{array}$ & 146 & 15 & 1 & 2 & 164 \\
\hline J6190 & $\begin{array}{l}\text { Otras actividades de telecomunica- } \\
\text { ciones }\end{array}$ & 143 & 12 & 0 & 0 & 155 \\
\hline K6612 & $\begin{array}{l}\text { Corretaje de valores y de contratos de } \\
\text { productos básicos }\end{array}$ & 141 & 4 & 0 & 0 & 145 \\
\hline S9602 & $\begin{array}{l}\text { Peluquería y otros tratamientos de } \\
\text { belleza }\end{array}$ & 108 & 23 & 0 & 0 & 131 \\
\hline G4772 & $\begin{array}{l}\text { Venta al por menor de productos far- } \\
\text { macéuticos y médicos, cosméticos } \\
\text { y artículos de tocador en comercios } \\
\text { especializados }\end{array}$ & 62 & 16 & 3 & 6 & 87 \\
\hline H5221 & $\begin{array}{l}\text { Actividades de servicios vinculadas al } \\
\text { transporte terrestre }\end{array}$ & 74 & 6 & 5 & 2 & 87 \\
\hline \multicolumn{2}{|c|}{ Subtotal (Primeras 11 actividades) } & 2175 & 282 & 33 & 31 & 2521 \\
\hline \multicolumn{2}{|c|}{ Resto (184 actividades) } & 1399 & 321 & 101 & 86 & 1910 \\
\hline & TOTAL GENERAL & 3574 & 603 & 134 & 117 & 4431 \\
\hline
\end{tabular}

Fuente: Trabajo de campo realizado a los comerciantes con emplazamiento fijo de la ciudad de Ipiales. 
De ese modo, el censo empresarial identificó 194 actividades económicas, según la Clasificación Internacional de la Industria Uniforme (CIIU Rev. 4), dentro de las cuales, 11 de ellas concentran el 56.89\% del número total de empresas. Además, se observa que el mayor número de UP se encuentran en las actividades de: alimentos y bebidas, restaurantes, venta al por menor de alimentos en comercios especializados, mantenimiento y reparación de vehículos automotores, actividades de telecomunicación, peluquería y otros tratamientos de belleza, entre otras; sobresaliendo la presencia de microempresas (2.175 UP), por lo que el progreso productivo en la localidad está determinado por el bajo desarrollo empresarial y la informalidad. Por su parte, la pequeña empresa la conforman 603 UP, la mediana empresas la conforman 134 establecimientos, y, tan solo 117 organizaciones, hacen parte de la gran empresa, destacándose las grandes superficies y las empresas estatales (Tabla No. 7 y Gráfico No. 3).

Gráfico No. 3.

TAMAÑO DE LAS UNIDADES PRODUCTIVAS SEGÚN RANGO DE ACTIVOS

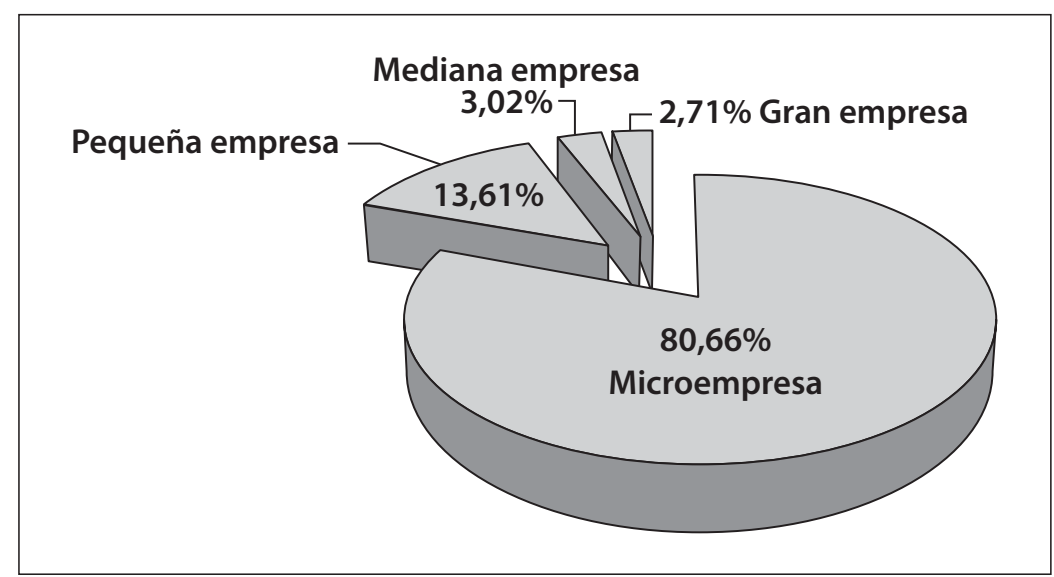

Fuente: Trabajo de campo realizado a los comerciantes con emplazamiento fijo de la ciudad de Ipiales

\subsection{Organización Jurídica}

Frente al tipo de organización jurídica, en la ciudad de Ipiales hay un mayor predominio de unidades productivas constituidas como personas naturales representadas en 3.483 establecimientos $(78,6 \%)$, en cuanto a las personas jurídicas se tiene que la mayoría son sociedades limitadas, empresas unipersonales y sociedades por acciones simplificadas (Tabla No. 8). 
Tabla No. 8

ORGANIZACIÓN JURÍDICA DE LA UNIDAD PRODUCTIVA

\begin{tabular}{ccc}
\hline & NÚMERO & PORCENTAJE \\
\hline 1. Persona Natural & 3.483 & $78,6 \%$ \\
2. Persona Jurídica & 948 & $21,4 \%$ \\
\hline TOTAL & $\mathbf{4 . 4 3 1}$ & $\mathbf{1 0 0 , 0 \%}$
\end{tabular}

Fuente: Trabajo de campo realizado a los comerciantes con emplazamiento fijo de la ciudad de Ipiales.

\subsection{Vigencia de Registros}

De acuerdo con los datos reportados por las empresas, el 61,7\% de unidades productivas de la ciudad de Ipiales tienen actualizado el Registro Único Tributario (RUT). De igual manera, existe un alto porcentaje de empresas con Registro de Industria y Comercio (46,9\%), le sigue el Registro Mercantil con un 45,7\%, pero tan solo el 26,7\% de las empresas llevan Registro de Contabilidad, el 19,9\% tiene vigente el Registro Sanitario y el 9,8\% cumplen con el registro de SAYCO y ACINPRO. Un bajo número de empresas tiene vigente los registros turísticos y la licencia de construcción, aclarando que no todas las empresas están obligadas a obtener estos documentos (Gráfico No. 4).

\section{Gráfico No. 4}

UNIDADES PRODUCTIVAS QUE TIENEN VIGENTE LOS REGISTROS BÁSICOS DE FUNCIONAMIENTO

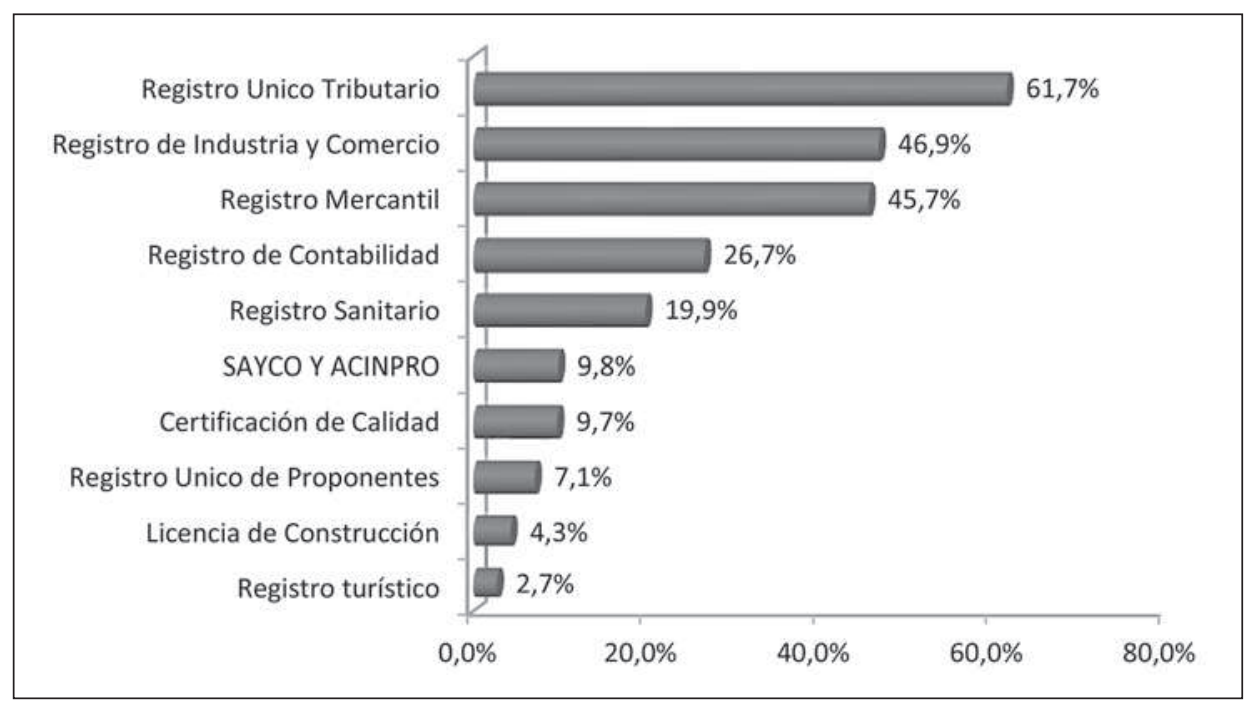

Fuente: Trabajo de campo realizado a los comerciantes con emplazamiento fijo de la ciudad de Ipiales. 


\subsection{Tiempo de Funcionamiento}

El alto grado de permanencia de las unidades productivas en la localidad no es muy alentador, existen una alta concentración en empresas con antigüedad menor a 3 años. Dejando solo 929 establecimientos con permanencia estructural debido a que su funcionamiento es superior a 10 años (Gráfico No. 5). Esta realidad refleja la alta volatilidad en los negocios en la ciudad, la cual es consecuencia de la temporalidad del comercio fronterizo, y a la vez deriva en una alta inestabilidad en el empleo y los ingresos de un gran número de personas que viven de estas unidades productivas.

Gráfico No. 5

\section{TIEMPO DE FUNCIONAMIENTO DE LA UNIDAD PRODUCTIVA EN LA LOCALIDAD}

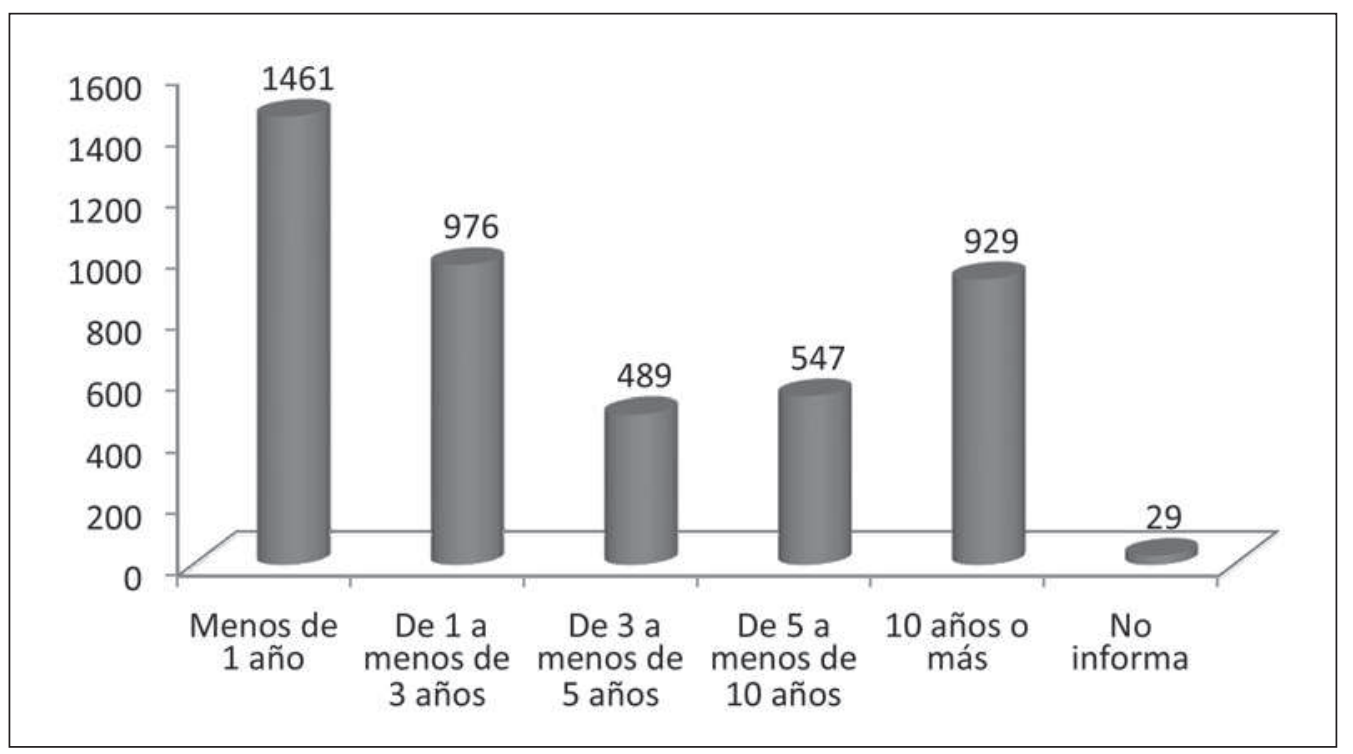

Fuente: Trabajo de campo realizado a los comerciantes con emplazamiento fijo de la ciudad de Ipiales.

Otra característica empresarial de la ciudad de Ipiales refiere que las comunidades de las zonas 7, 1 y 4 conviven con empresas de menos de un año, de igual manera se tiene que UP en los sectores 2,4 y 7 tienen 10 años o más de funcionamiento. En conclusión, del total de unidades productivas registradas 1.461 llevan menos de un año, 976 de uno a tres años, y 929 llevan más de 10 años (Tabla No. 9). 


\section{Tabla No. 9 \\ TIEMPO DE FUNCIONAMIENTO DE LAS UNIDADES PRODUCTIVAS EN LA LOCALIDAD POR SECTOR}

\begin{tabular}{cccccccc}
\hline Sectores & $\begin{array}{c}\text { Menos } \\
\text { de } 1 \text { año }\end{array}$ & $\begin{array}{c}\text { De } \mathbf{1} \text { a } \\
\text { menos } \\
\text { de } 3 \\
\text { años }\end{array}$ & $\begin{array}{c}\text { De } 3 \text { a } \\
\text { menos de } \\
\mathbf{5} \text { años }\end{array}$ & $\begin{array}{c}\text { De } 5 \text { a } \\
\text { menos } \\
\text { de } 10 \\
\text { años }\end{array}$ & $\begin{array}{c}10 \\
\text { años o } \\
\text { más }\end{array}$ & $\begin{array}{c}\text { No } \\
\text { informa }\end{array}$ & $\begin{array}{c}\text { TOTAL } \\
\text { GENERAL }\end{array}$ \\
\hline 1 & 304 & 118 & 45 & 43 & 37 & 1 & $\mathbf{5 4 8}$ \\
2 & 212 & 154 & 71 & 71 & 103 & 4 & $\mathbf{6 1 5}$ \\
4 & 147 & 117 & 56 & 64 & 102 & 1 & $\mathbf{4 8 7}$ \\
5 & 238 & 216 & 144 & 116 & 278 & 12 & $\mathbf{1 0 0 4}$ \\
6 & 22 & 22 & 8 & 14 & 39 & 0 & $\mathbf{1 0 5}$ \\
7 & 51 & 34 & 23 & 20 & 25 & 2 & $\mathbf{1 5 5}$ \\
8 & 481 & 313 & 140 & 216 & 343 & 9 & $\mathbf{1 5 0 2}$ \\
\hline TOTAL & 6 & 2 & 2 & 3 & 2 & & $\mathbf{1 5}$ \\
GENERAL & $\mathbf{1 4 6 1}$ & $\mathbf{9 7 6}$ & $\mathbf{4 8 9}$ & $\mathbf{5 4 7}$ & $\mathbf{9 2 9}$ & $\mathbf{2 9}$ & $\mathbf{4 4 3 1}$ \\
\hline
\end{tabular}

Fuente: Trabajo de campo realizado a los comerciantes con emplazamiento fijo de la ciudad de Ipiales.

\subsection{Empleo Generado}

A partir de la información suministrada por los encuestados, se identificó que la estructura productiva de la ciudad no dinamiza el mercado laboral, ya que el $59,7 \%$ de las empresas ocupan tan solo a una persona; cabe señalar que en su mayoría son empleos generados dentro del hogar, es decir, que aparte del propietario se encuentra trabajando la esposa o uno de sus hijos. En segundo lugar, se localizaron empresas que tienen entre 2 a 5 empleos $(29,7 \%)$ y sólo se identificaron 8 empresas con más de 201 trabajadores, esto indica que las oportunidades de empleo en la región no son muy buenas, luego el $92.7 \%$ de las unidades productivas, con relación al número de empleos, es de tipo microempresa (Tabla No. 10).

Las actividades económicas que más generan empleo en la ciudad son: Venta al por menor en comercios no especializados con predominio de la venta de alimentos, bebidas o tabaco, Venta al por menor de prendas de vestir, calzado y artículos de cuero en comercios especializados, Actividades de restaurantes y de servicio móvil de comidas, Venta al por menor de alimentos en comercios especializados, Actividades de telecomunicaciones inalámbricas, Mantenimiento y reparación de vehículos automotores, Otras actividades de telecomunicaciones, Peluquería y otros tratamientos de belleza, Actividades de servicios vinculadas al transporte terrestre, Venta al por menor de productos farmacéuticos y médicos, cosméticos y artículos de tocador en comercios especializados. Mientras que las empresas que generan más empleos en la ciudad de Ipiales están caracterizadas por pertenecer a la administración pública, rama judicial, y sector educativo (Tabla No. 11). 


\section{Tabla No. 10 \\ PERSONAL OCUPADO EN LAS UNIDADES PRODUCTIVAS}

\begin{tabular}{lcc}
\hline & NÚMERO & PORCENTAJE \\
\hline 1 empleo & 2.647 & $59,70 \%$ \\
2 a 5 empleos & 1.318 & $29,70 \%$ \\
6 a 10 empleos & 146 & $3,30 \%$ \\
11 a 20 empleos & 66 & $1,50 \%$ \\
21 a 50 empleos & 52 & $1,20 \%$ \\
51 a 200 empleos & 23 & $0,50 \%$ \\
Más de 201 trabajadores & 8 & $0,20 \%$ \\
No informa & 171 & $3,90 \%$ \\
\hline \multicolumn{1}{c}{ TOTAL } & $\mathbf{4 . 4 3 1}$ & $\mathbf{1 0 0 , 0 0 \%}$ \\
\hline
\end{tabular}

Fuente: Trabajo de campo realizado a los comerciantes con emplazamiento fijo de la ciudad de Ipiales.

De acuerdo con el censo empresarial realizado en la ciudad de Ipiales, la venta de alimentos al por menor, venta de prendas de vestir y corretaje de valores (actividades de cambio de moneda) como lo son los cambistas, solo generan un empleo en el municipio siendo estas actividades las que más empresas poseen.

\subsection{Aportes a Seguridad Social y Parafiscales}

Los aportes a la seguridad social (salud, pensión y riesgos profesionales) y los aportes parafiscales (SENA, ICBF y caja de compensación), son una obligación de todo empleador y/o trabajador independiente de acuerdo con la normatividad nacional (Ley 100/93).

Estos pagos permiten al empleador cubrir el riesgo de enfermedades, pensión o accidentes laborales de sus trabajadores. De igual forma, su pago oportuno permite acceder al sistema de salud y cotizar para la pensión en la etapa de jubilación. Así mismo, los parafiscales le dan derecho al trabajador de acceder a una caja de compensación y son una fuente importante de financiamiento del SENA y el ICBF.

Del total de unidades productivas de Ipiales, el 20,9\% realizan el aporte a salud, es decir, 3.504 empresas evaden el pago de seguridad social para sus empleados. En cuanto a los aportes parafiscales se tiene una situación muy preocupante puesto que las contribuciones al SENA y al ICBF tan solo lo realizan 11\% y 10,9\% de las empresas, respectivamente; esto muestra que la mayoría de las empresas lo evitan, ocasionando una reducción en recursos que finalmente ayudan en el apalancamiento de programas sociales. El aseguramiento al régimen de protección de riesgos profesionales es similar a la situación de los parafiscales, puesto que tan solo el 13,2\% cumplen con esta obligación (Gráfico No. 6). 
Tabla No. 11.

PERSONAL OCUPADO EN LAS UNIDADES PRODUCTIVAS SEGÚN ACTIVIDAD ECONÓMICA

\begin{tabular}{|c|c|c|c|c|c|c|c|c|c|c|}
\hline CÓD. CIIU & ACTIVIDAD & 1 empleo & $\begin{array}{c}2 \text { a } 5 \\
\text { empleos }\end{array}$ & $\begin{array}{c}6 \text { a } 10 \\
\text { empleos }\end{array}$ & $\begin{array}{c}11 \text { a } 20 \\
\text { empleos }\end{array}$ & $\begin{array}{l}21 \text { a } 50 \\
\text { empleos }\end{array}$ & $\begin{array}{l}51 \text { a } 200 \\
\text { empleos }\end{array}$ & $\begin{array}{c}\text { Más } \\
\text { de } 201 \\
\text { empleos }\end{array}$ & No informa & TOTAL \\
\hline G4711 & $\begin{array}{l}\text { Venta al por menor en } \\
\text { comercios no espe- } \\
\text { cializados con predo- } \\
\text { minio de la venta de } \\
\text { alimentos, bebidas o } \\
\text { tabaco }\end{array}$ & 732 & 91 & 7 & 2 & 3 & 1 & 0 & 68 & 904 \\
\hline G4771 & $\begin{array}{l}\text { Venta al por menor } \\
\text { de prendas de vestir, } \\
\text { calzado y artículos de } \\
\text { cuero en comercios } \\
\text { especializados }\end{array}$ & 137 & 110 & 8 & 0 & 0 & 0 & 0 & 3 & 258 \\
\hline 15610 & $\begin{array}{l}\text { Actividades de restau- } \\
\text { rantes y de servicio } \\
\text { móvil de comidas }\end{array}$ & 83 & 143 & 18 & 4 & 0 & 0 & 0 & 5 & 253 \\
\hline G4721 & $\begin{array}{l}\text { Venta al por menor de } \\
\text { alimentos en comer- } \\
\text { cios especializados }\end{array}$ & 112 & 46 & 4 & 0 & 1 & 0 & 0 & 9 & 172 \\
\hline J6120 & $\begin{array}{l}\text { Actividades de teleco- } \\
\text { municaciones inalám- } \\
\text { bricas }\end{array}$ & 121 & 29 & 4 & 2 & 0 & 1 & 0 & 8 & 165 \\
\hline G4520 & $\begin{array}{l}\text { Mantenimiento y re- } \\
\text { paración de vehículos } \\
\text { automotores }\end{array}$ & 69 & 81 & 6 & 1 & 1 & 0 & 0 & 6 & 164 \\
\hline J6190 & $\begin{array}{l}\text { Otras actividades de } \\
\text { telecomunicaciones }\end{array}$ & 127 & 23 & 0 & 0 & 0 & 0 & 0 & 5 & 155 \\
\hline
\end{tabular}




\begin{tabular}{|c|c|c|c|c|c|c|c|c|c|c|}
\hline CÓD. CIIU & ACTIVIDAD & 1 empleo & $\begin{array}{c}2 \text { a } 5 \\
\text { empleos }\end{array}$ & $\begin{array}{c}6 \text { a } 10 \\
\text { empleos }\end{array}$ & $\begin{array}{c}11 \text { a } 20 \\
\text { empleos }\end{array}$ & $\begin{array}{l}21 \text { a } 50 \\
\text { empleos }\end{array}$ & $\begin{array}{l}51 \text { a } 200 \\
\text { empleos }\end{array}$ & $\begin{array}{c}\text { Más } \\
\text { de } 201 \\
\text { empleos }\end{array}$ & No informa & TOTAL \\
\hline K6612 & $\begin{array}{l}\text { Corretaje de valores y } \\
\text { de contratos de pro- } \\
\text { ductos básicos }\end{array}$ & 140 & 3 & 0 & 0 & 0 & 1 & 0 & 1 & 145 \\
\hline S9602 & $\begin{array}{l}\text { Peluquería y otros tra- } \\
\text { tamientos de belleza }\end{array}$ & 92 & 35 & 0 & 0 & 0 & 0 & 0 & 4 & 131 \\
\hline H5221 & $\begin{array}{l}\text { Actividades de ser- } \\
\text { vicios vinculadas al } \\
\text { transporte terrestre }\end{array}$ & 60 & 17 & 3 & 1 & 1 & 1 & 0 & 4 & 87 \\
\hline G4772 & $\begin{array}{l}\text { Venta al por menor } \\
\text { de productos farma- } \\
\text { céuticos y médicos, } \\
\text { cosméticos y artículos } \\
\text { de tocador en comer- } \\
\text { cios especializados }\end{array}$ & 47 & 35 & 0 & 2 & 1 & 0 & 0 & 2 & 87 \\
\hline \multicolumn{2}{|c|}{ Subtotal ( $11^{\mathrm{a}}$ actividades) } & 1720 & 613 & 50 & 12 & 7 & 4 & 0 & 115 & 2521 \\
\hline \multicolumn{2}{|c|}{ Resto (184 actividades) } & 927 & 705 & 96 & 54 & 45 & 19 & 8 & 56 & 1910 \\
\hline & Total general & 2647 & 1318 & 146 & 66 & 52 & 23 & 8 & 171 & 4431 \\
\hline
\end{tabular}

Fuente: Trabajo de campo realizado a los comerciantes con emplazamiento fijo de la ciudad de Ipiales. 
Gráfico No. 6

APORTES DE LAS UNIDADES PRODUCTIVAS A SEGURIDAD SOCIAL Y PARAFISCALES

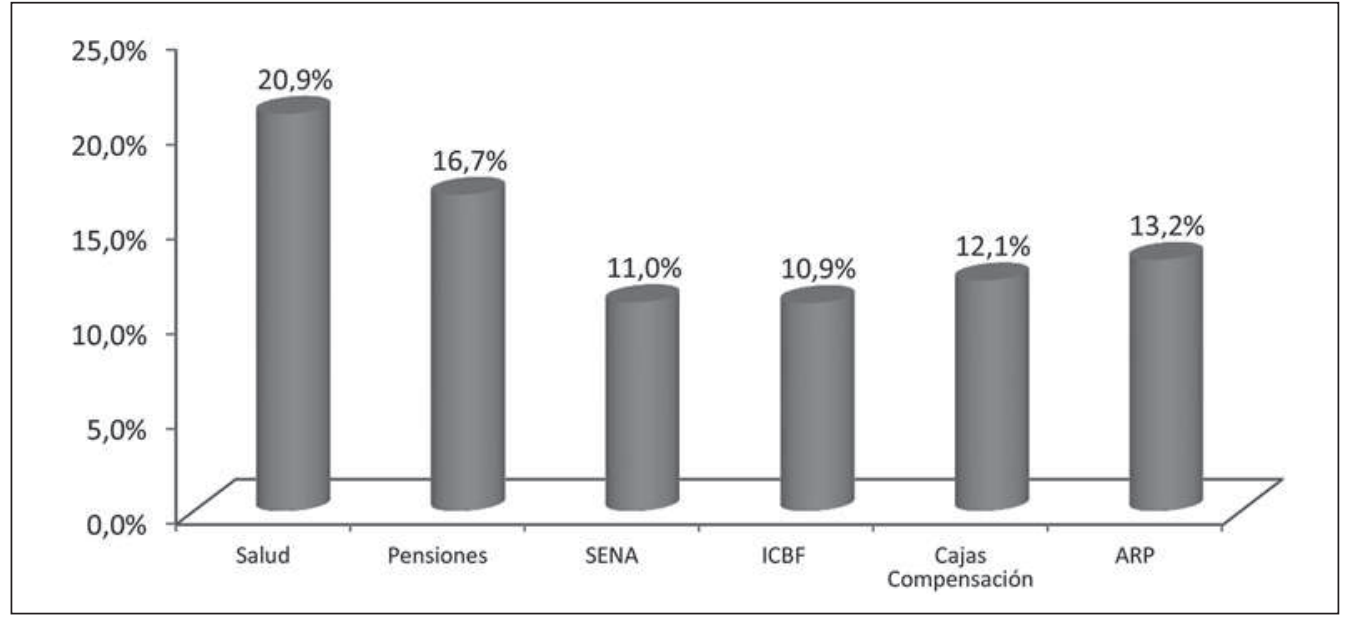

Fuente: Trabajo de campo realizado a los comerciantes con emplazamiento fijo de la ciudad de Ipiales.

\subsection{Informalidad empresarial en la ciudad de Ipiales}

Las características del sector empresarial del municipio de Ipiales son favorables para el fomento de la informalidad laboral, es decir, la existencia de un sector empresarial incipiente con un bajo grado de organización, una alta dependencia del sector comercio y un bajo nivel de empleos, ocasiona que las personas desempleadas o subempleadas, busquen formas de ingresos que les permita acceder a productos y servicios que no pueden adquirir con su situación actual.

Sin embargo, estos empresarios tienen grandes problemas en temas como: el acceso al crédito, riesgo de penalización por el incumplimiento de la ley, limitado acceso a servicios de apoyo públicos y privados, baja productividad tanto de la empresa como de los empleados, baja posibilidad de ampliar el mercado interno y de competir en los mercados externos, altos costos de las contingencias laborales (salud, riesgos profesionales, demandas laborales), dotaciones logísticas y tecnológicas inadecuadas, altos costos de transacción para el desarrollo de la actividad productiva, débil asociatividad, entre otras.

Normativamente se identificaron cuatro requisitos básicos que deben cumplir las empresas para operar en condiciones de formalidad. Tener matricula mercantil, tener registro de contabilidad, pagar impuestos y realizar los aportes a la seguridad social. Sin embargo, el Artículo 19 del Código de Comercio (1971) advierte que "Es obligación de todo comerciante: Matricularse en el registro mercantil; Inscribir en el registro mercantil todos los actos, libros y documentos respecto de los cuales la ley exija esa formalidad; Llevar contabilidad regular de sus negocios conforme a las prescripciones legales”. Así, el estudio tomara la matricula comercial como 
el instrumento que formaliza las empresas, sin que ello implique desconocer la existencia de otros requisitos que fortalecen la formalización.

Bajo el concepto anterior, la investigación permitió identificar que para la ciudad de Ipiales existen 2.406 empresas que no pagan su matrícula mercantil, es decir, que del total de las unidades productivas el 54,3\% se encuentra en la informalidad. Así mismo, 1.696 UP no pagan impuestos y 3.247 no llevan registro de contabilidad. Frente a seguridad social más del 79\% no pagan los respectivos aportes, mientras que un porcentaje superior a $85 \%$ evade el pago de parafiscales; cabe señalar que frente a los pagos de seguridad social y parafiscales muchos empresarios manifestaron que los ingresos percibidos no son suficientes para realizar estos pagos, ni para sus empleados, ni para ellos (Tabla No. 12).

Tabla No. 12

NÚMERO DE UNIDADES PRODUCTIVAS INFORMALES

\begin{tabular}{lcc}
\hline \multicolumn{1}{c}{ NO PAGAN } & UP & $\%$ \\
\hline Registro Mercantil & 2.406 & $54,3 \%$ \\
RUT & 1.696 & $38,3 \%$ \\
Salud & 3.504 & $79,1 \%$ \\
Pensiones & 3.693 & $83,3 \%$ \\
SENA & 3.944 & $89,0 \%$ \\
ICBF & 3.946 & $89,1 \%$ \\
Caja de Compensación & 3.893 & $87,9 \%$ \\
ARP & 3.845 & $86,8 \%$ \\
\hline
\end{tabular}

Fuente: Trabajo de campo realizado a los comerciantes con emplazamiento fijo de la ciudad de Ipiales.

Algunos de los empresarios que se logró entrevistar informaron que los establecimientos que ellos manejan son demasiado pequeños y por tal motivo no tienen obligación de pagar los impuestos debido a que estos negocios se encuentran en condiciones de subsistencia para sus familias, además no manejan un alto número de empleados, ya que la mayoría de los empleos son familiares. Otro motivo que impulsa a los empresarios de la región a no querer formalizarse es que no encuentran ningún beneficio en cuanto al pago de impuestos, esto se debe a que las entidades no han generado campañas de concienciación sobre la importancia de la formalización y las oportunidades de crecimiento que ello refleja a nivel de créditos y capacitación.

A continuación se presentan las 11 principales actividades que no poseen matricula mercantil (Tabla No. 13): 
Víctor David Jaramillo Mejía

Diagnóstico empresarial de la ciudad de Ipiales: una aproximación a partir del censo económico-empresarial

Tabla No. 13

PRIMERAS ACTIVIDADES ECONÓMICAS QUE NO PAGAN MATRÍCULA MERCANTIL

\begin{tabular}{|c|c|c|}
\hline CÓD. CIIU & ACTIVIDAD & NO PAGAN \\
\hline G4711 & $\begin{array}{l}\text { Venta al por menor en comercios no especializados con predo- } \\
\text { minio de la venta de alimentos, bebidas o tabaco }\end{array}$ & 658 \\
\hline 15610 & Actividades de restaurantes y de servicio móvil de comidas & 123 \\
\hline J6120 & Actividades de telecomunicaciones inalámbricas & 122 \\
\hline G4721 & Venta al por menor de alimentos en comercios especializados & 112 \\
\hline G4520 & Mantenimiento y reparación de vehículos automotores & 107 \\
\hline J6190 & Otras actividades de telecomunicaciones & 107 \\
\hline S9602 & Peluquería y otros tratamientos de belleza & 82 \\
\hline G4771 & $\begin{array}{l}\text { Venta al por menor de prendas de vestir, calzado y artículos de } \\
\text { cuero en comercios especializados }\end{array}$ & 77 \\
\hline H5221 & Actividades de servicios vinculadas al transporte terrestre & 50 \\
\hline G4773 & $\begin{array}{l}\text { Venta al por menor de otros productos nuevos en comercios } \\
\text { especializados }\end{array}$ & 46 \\
\hline \multirow[t]{3}{*}{ S9523 } & Reparación de calzado y de artículos de cuero & 41 \\
\hline & Subtotal (primeras 11 actividades) & 1525 \\
\hline & Resto (184 actividades) & 881 \\
\hline & TOTAL GENERAL & 2406 \\
\hline
\end{tabular}

Fuente: Trabajo de campo realizado a los comerciantes con emplazamiento fijo de la ciudad de Ipiales.

\subsection{Informalidad: análisis de hechos estilizados}

En general, el análisis de diferencias advierte que las unidades productivas informales se caracterizan por: ser personas naturales, microempresas, tener sus instalaciones en una vivienda, con funcionamiento menor a 3 años, pertenecer a los sectores secundario y terciario, específicamente en actividades como: industria manufacturera, información y comunicaciones, comercio al por mayor y menor, actividades profesionales, entre otras; adicional a ello, estas empresas tienen menor posibilidad de negociar con dólares y se caracterizan por mantener trabajadores sin ningún tipo de contrato escrito. Es interesante observar que existe mayor informalidad empresarial en los sectores aledaños a la zona céntrica de la ciudad, como los sectores: 4, 5 y 7 (Tabla No. 14). 
Tabla No. 14

EFECTOS DE LA INFORMALIDAD SOBRE EL CONTEXTO EMPRESARIAL

\begin{tabular}{|c|c|c|c|}
\hline Variables & Formal (0) & Informal (1) & Diferencia \\
\hline \multicolumn{4}{|c|}{ CLASIFICACIÓN JURÍDICA } \\
\hline Persona natural & 0.8520562 & 0.9562399 & $-0.1041837^{*}$ \\
\hline Persona jurídica & 0.1479438 & 0.0437601 & $0.1041837^{*}$ \\
\hline \multicolumn{4}{|c|}{ TAMAÑO DE LA EMPRESA } \\
\hline Micro empresa & 0.7096289 & 0.8676391 & $-0.1580102^{* *}$ \\
\hline Pequeña empresa & 0.1810431 & 0.1193949 & $0.0616482^{*}$ \\
\hline Mediana empresa & 0.0556670 & 0.0081037 & $0.0475633^{*}$ \\
\hline Gran empresa & 0.0536610 & 0.0048622 & $0.0487988^{*}$ \\
\hline \multicolumn{4}{|c|}{ TIPO DE EMPLAZAMIENTO } \\
\hline Local u Oficina & 0.7116349 & 0.4424635 & $0.2691714^{* *}$ \\
\hline Vivienda con actividad económica & 0.1785356 & 0.4743382 & $-0.2958026^{* *}$ \\
\hline Puesto Fijo & 0.1013039 & 0.0788763 & $0.0224276^{* *}$ \\
\hline Fábrica & 0.0085256 & 0.0043220 & $0.0042036^{*}$ \\
\hline \multicolumn{4}{|c|}{ TIEMPO DE FUNCIONAMIENTO DE LA EMPRESA } \\
\hline Menos de 1 año & 0.1629890 & 0.4251756 & $-0.2621866^{*}$ \\
\hline De 1 a menos de 3 años & 0.2281846 & 0.2441923 & $-0.0160077^{*}$ \\
\hline De 3 a menos de 5 años & 0.1339017 & 0.0972447 & $0.0366570^{* *}$ \\
\hline De 5 a menos de 10 años & 0.1770311 & 0.0831983 & $0.0938328^{* *}$ \\
\hline 10 años o más & 0.2978937 & 0.1501891 & $0.1477046^{* *}$ \\
\hline \multicolumn{4}{|c|}{ TIPO DE CONTRATO LABORAL } \\
\hline Con contrato laboral & 0.4613842 & 0.1193949 & $0.3419893^{* *}$ \\
\hline Sin contrato laboral & 0.5386158 & 0.8806051 & $-0.3419893^{* *}$ \\
\hline \multicolumn{4}{|c|}{ NEGOCIACIÓN EN DÓLARES } \\
\hline Negociación en Dólares & 1.7893680 & 1.9081580 & $-0.1187900^{* *}$ \\
\hline \multicolumn{4}{|c|}{ SECTORES ECONÓMICOS } \\
\hline Sector Primario & 0.0010030 & 0.0005402 & $0.0004628^{*}$ \\
\hline Sector Secundario & 0.0917753 & 0.1091302 & $-0.0173549^{*}$ \\
\hline Sector Terciario & 0.8903296 & 0.9072217 & $-0.0168921^{*}$ \\
\hline
\end{tabular}


Víctor David Jaramillo Mejía

Diagnóstico empresarial de la ciudad de Ipiales: una aproximación a partir del censo económico-empresarial

\begin{tabular}{|c|c|c|c|}
\hline \multicolumn{4}{|c|}{ ACTIVIDAD ECONÓMICA } \\
\hline $\begin{array}{l}\text { Agricultura, ganadería, silvicultura } \\
\text { y pesca }\end{array}$ & 0.0005015 & 0.0005402 & $-0.0000387^{* *}$ \\
\hline Explotación de minas y canteras & 0.0005015 & 0.0000000 & $0.0005015^{* *}$ \\
\hline Industrias manufactureras & 0.0807422 & 0.1069692 & $-0.0262270^{*}$ \\
\hline $\begin{array}{l}\text { Suministro de electricidad, gas, va- } \\
\text { por y aire acondicionado }\end{array}$ & 0.0010030 & 0.0016207 & $-0.0006177^{*}$ \\
\hline $\begin{array}{l}\text { Suministro de agua; evacuación } \\
\text { de aguas residuales, gestión de } \\
\text { desechos y descontaminación }\end{array}$ & 0.0015045 & 0.0000000 & $0.0015045^{* * *}$ \\
\hline Construcción & 0.0085256 & 0.0005402 & $0.0079854^{* *}$ \\
\hline $\begin{array}{l}\text { Comercio al por mayor y al por } \\
\text { menor; reparación de vehículos } \\
\text { automotores y motocicletas }\end{array}$ & 0.5045135 & 0.5067531 & $-0.0022396^{*}$ \\
\hline Transporte y almacenamiento & 0.0697091 & 0.0307942 & $0.0389149^{* *}$ \\
\hline $\begin{array}{l}\text { Actividades de alojamiento y de } \\
\text { servicio de comidas }\end{array}$ & 0.0992979 & 0.0642896 & $0.0350083^{* *}$ \\
\hline Información y comunicaciones & 0.0541625 & 0.1145327 & $-0.0603702^{* *}$ \\
\hline $\begin{array}{l}\text { Actividades financieras y de segu- } \\
\text { ros }\end{array}$ & 0.0431294 & 0.0054025 & $0.0377269 * * *$ \\
\hline Actividades inmobiliarias & 0.0050150 & 0.0027012 & $0.0023138^{* * *}$ \\
\hline $\begin{array}{l}\text { Actividades profesionales, científi- } \\
\text { cas y técnicas }\end{array}$ & 0.0235707 & 0.0340357 & $-0.0104650 *$ \\
\hline $\begin{array}{l}\text { Actividades de servicios adminis- } \\
\text { trativos y de apoyo }\end{array}$ & 0.0095286 & 0.0081037 & $0.0014249 *$ \\
\hline $\begin{array}{l}\text { Administración pública y defensa; } \\
\text { planes de seguridad social de afi- } \\
\text { liación obligatoria }\end{array}$ & 0.0025075 & 0.0032415 & $-0.0007340^{*}$ \\
\hline Enseñanza & 0.0115346 & 0.0102647 & $0.0012699 *$ \\
\hline $\begin{array}{l}\text { Actividades de atención de la sa- } \\
\text { lud humana y de asistencia social }\end{array}$ & 0.0245737 & 0.0124257 & $0.0121480^{*}$ \\
\hline $\begin{array}{l}\text { Actividades artísticas, de entrete- } \\
\text { nimiento y recreativas }\end{array}$ & 0.0120361 & 0.0059427 & $0.0060934^{* *}$ \\
\hline Otras actividades de servicios & 0.0471414 & 0.0886008 & $-0.0414594^{* *}$ \\
\hline $\begin{array}{l}\text { Actividades de los hogares como } \\
\text { empleadores; actividades no di- } \\
\text { ferenciadas de los hogares como } \\
\text { productores de bienes y servicios } \\
\text { para uso propio }\end{array}$ & 0.0005015 & 0.0032415 & $-0.0027400^{* *}$ \\
\hline
\end{tabular}




\begin{tabular}{lccc}
\hline \multicolumn{4}{c}{ SECTORES GEOGRÁFICOS } \\
\hline Sector_1 & 0.0571715 & 0.2155592 & $-0.1583877^{*}$ \\
Sector_2 & 0.1008024 & 0.1653160 & $-0.0645136^{*}$ \\
Sector_3 & 0.0967904 & 0.1091302 & $-0.0123398^{*}$ \\
Sector_4 & 0.2452357 & 0.2285251 & $0.0167106^{*}$ \\
Sector_5 & 0.0325978 & 0.0167477 & $0.0158501^{*}$ \\
Sector_6 & 0.0280843 & 0.0513236 & $-0.0232393^{*}$ \\
Sector_7 & 0.4388164 & 0.2058347 & $0.2329817^{*}$ \\
Sector_8 & 0.0005015 & 0.0075635 & $-0.0070620^{*}$ \\
\hline
\end{tabular}

No. Observaciones $=3845$

***: Significativo al $10 \%$ de confianza. **: Significativo al 5\%. *: Significativo al $1 \%$.

Fuente: Cálculos propios basados en el método Bootstrapping aplicado a la Base de Datos del Censo Empresarial.

\subsection{Análisis microeconométrico de la informalidad empresarial en la ciudad de Ipiales}

En general, el análisis corrobora lo observado en el análisis descriptivo y el test de diferencias, donde el poseer un local u oficina reduce en $11 \%$ la probabilidad de ser informal, lo mismo sucede con emplazamiento tipo fabrica. Por su parte, pertenecer al sector secundario incrementa la probabilidad de informalidad en $23 \%$, lo mismo sucede con las empresas que se suscriben al sector terciario, pero con un impacto menor de entre el 6\% y el 7\%. Como era de esperar las micro y pequeñas empresas tienen mayores posibilidades de estar como informales, no obstante, presentan efectos decrecientes frente al tiempo, donde a medida que amplían su antigüedad, también se aumenta la probabilidad de pasar a la formalidad, para el caso de la ciudad de Ipiales este efecto se presenta entre las empresas con antigüedad mayor a 5 y menor a 10 años.

A su vez, se puede afirmar que el crecimiento empresarial, observado desde la óptica de empleos, reduce la probabilidad de informalidad (Tabla No. 15). 
Víctor David Jaramillo Mejía

Tabla 15. Ipiales: Análisis de informalidad empresarial

Variable dependiente: Informalidad = 1

Análisis realizado con estadísticas del censo empresarial

\begin{tabular}{|c|c|c|c|c|}
\hline Variables & $\begin{array}{c}\text { Efectos } \\
\text { Marginales } \\
\text { Informalidad } \\
\text { Modelo } 1\end{array}$ & $\begin{array}{c}\text { Efectos } \\
\text { Marginales } \\
\text { Informalidad } \\
\text { Modelo } 2\end{array}$ & $\begin{array}{c}\text { Efectos } \\
\text { Marginales } \\
\text { Informalidad } \\
\text { Modelo } 3\end{array}$ & $\begin{array}{c}\text { Efectos } \\
\text { Marginales } \\
\text { Informalidad } \\
\text { Modelo } 4\end{array}$ \\
\hline \multicolumn{5}{|c|}{ Tipo de Emplazamiento } \\
\hline \multirow[t]{2}{*}{ Local u Oficina * } & $-0,121$ & $-0,117$ & $-0,116$ & $-0,113$ \\
\hline & $(0,000)$ & $(0,000)$ & $(0,000)$ & $(0,000)$ \\
\hline \multirow[t]{2}{*}{ Fabrica * } & $-0,110$ & $-0,108$ & $-0,122$ & $-0,119$ \\
\hline & $(0,000)$ & $(0,000)$ & $(0,270)$ & $(0,279)$ \\
\hline \multirow{2}{*}{$\begin{array}{l}\text { Vivienda con actividad } \\
\text { económica * }\end{array}$} & 0,214 & 0,218 & 0,203 & 0,207 \\
\hline & $(0,000)$ & $(0,000)$ & $(0,000)$ & $(0,000)$ \\
\hline \multicolumn{5}{|c|}{ Organización Jurídica } \\
\hline \multirow[t]{2}{*}{ Persona natural * } & 0,150 & & 0,058 & 0,059 \\
\hline & $(0,000)$ & & $(0,000)$ & $(0,099)$ \\
\hline \multirow[t]{2}{*}{ Persona jurídica * } & & $-0,151$ & & \\
\hline & & $(0,000)$ & & \\
\hline \multicolumn{5}{|c|}{ Sector Económico } \\
\hline \multirow[t]{2}{*}{ Sector Primario * } & $-0,182$ & $-0,181$ & $-0,225$ & \\
\hline & $(0,000)$ & $(0,000)$ & $(0,000)$ & \\
\hline \multirow[t]{2}{*}{ Sector Secundario * } & & & & 0,234 \\
\hline & & & & $(0,459)$ \\
\hline \multirow[t]{2}{*}{ Sector Terciario * } & 0,065 & 0,067 & 0,064 & 0,170 \\
\hline & $(0,025)$ & $(0,021)$ & $(0,028)$ & $(0,097)$ \\
\hline \multicolumn{5}{|c|}{ Tamaño de la Empresa } \\
\hline \multirow[t]{2}{*}{ Micro empresa * } & & & 0,328 & 0,328 \\
\hline & & & $(0,000)$ & $(0,000)$ \\
\hline \multirow[t]{2}{*}{ Pequeña empresa * } & & & 0,254 & 0,255 \\
\hline & & & $(0,001)$ & $(0,001)$ \\
\hline \multirow[t]{2}{*}{ Mediana empresa * } & & & $-0,019$ & $-0,019$ \\
\hline & & & $(0,085)$ & $(0,111)$ \\
\hline
\end{tabular}




\begin{tabular}{|c|c|c|c|c|}
\hline \multicolumn{5}{|c|}{ Tiempo de Funcionamiento } \\
\hline \multirow[t]{2}{*}{ Tiempo } & $-0,322$ & & $-0,320$ & \\
\hline & $(0,000)$ & & $(0,000)$ & \\
\hline \multirow[t]{2}{*}{ Tiempo2 } & 0,038 & & 0,038 & \\
\hline & $(0,000)$ & & $(0,000)$ & \\
\hline \multirow[t]{2}{*}{ Menos de 1 año } & & 0,357 & & 0,305 \\
\hline & & $(0,000)$ & & $(0,000)$ \\
\hline \multirow[t]{2}{*}{ De 1 a menos de 3 años } & & 0,165 & & 0,108 \\
\hline & & $(0,000)$ & & $(0,000)$ \\
\hline \multirow[t]{2}{*}{ De 3 a menos de 5 años } & & 0,057 & & 0,051 \\
\hline & & $(0,069)$ & & $(0,006)$ \\
\hline \multirow[t]{2}{*}{ De 5 a menos de 10 años } & & $-0,034$ & & $-0,088$ \\
\hline & & $(0,000)$ & & $(0,011)$ \\
\hline \multirow[t]{2}{*}{10 años o más } & & $-0,040$ & & $-0,048$ \\
\hline & & $(0,009)$ & & $(0,012)$ \\
\hline \multicolumn{5}{|c|}{ Número de empleos generado } \\
\hline \multirow[t]{2}{*}{ Empleos } & $-0,010$ & $-0,011$ & $-0,004$ & $-0,005$ \\
\hline & $(0,111)$ & $(0,085)$ & $(0,000)$ & $(0,040)$ \\
\hline
\end{tabular}

(*) $\mathrm{dF} / \mathrm{dx}$ is for discrete change of dummy variable from 0 to 1

$\mathrm{Z}$ and $\mathrm{P}>|\mathrm{z}|$ correspond to the test of the underlying coefficient being 0

\section{CONCLUSIONES}

Se puede afirmar que la ciudad de Ipiales por su característica de frontera, tiene algunas particularidades que deben tenerse en cuenta a la hora de decidir invertir o de realizar un proyecto público.

La ciudad de Ipiales posee un alto grado de dualismo de frontera, donde hay una alta dependencia del comercio, no solo a nivel de Ipiales, si no que las personas tienen como necesidad el realizar la compra de algunos productos en la vecina ciudad de Tulcán (Ecuador), pero esta se constituye en una relación natural, donde histórica y culturalmente se han desarrollado las sinergias comerciales, que se denominan "relaciones de hermandad" y que han posibilitado generar dependencias de una ciudad frente a otra. Estas relaciones se encuentran contextualizadas como legales, pues son las que dinamizan las actividades económicas y el empleo, aunque es necesario entender que bajo este esquema se generan otras problemáticas como el contrabando que si bien se constituye en una actividad de generación de ingresos, reduce el progreso económico de la ciudad y de la región. 
Uno de los problemas por los cuales la estructura comercial de la ciudad de Ipiales no crece se refiere a la baja dinámica empresarial; así, el 80,66\% de la UP son microempresas caracterizadas por ser pequeños talleres o tiendas que no generan empleo e ingresos adecuados y estables.

Respecto a la informalidad, existe un $54,3 \%$ de empresas bajo esta condición, lo que imposibilita el apalancamiento y crecimiento del sector, pero también genera bajas posibilidades de mantenerse en el mercado. Por otro lado, la informalidad empresarial ha influido en el alto índice de informalidad laboral, luego, del total de unidades productivas de Ipiales, el mayor pago que realizan las empresas son a seguridad social, especialmente a salud con un 20,9\%, es decir que 3.504 empresarios evaden el pago a la seguridad social de sus empleados. En cuanto a los aportes parafiscales, SENA e ICBF, tan solo los cumplen el 11\% y 10,9\%, respectivamente; es decir, la informalidad y el bajo dinamismo empresarial reflejan el bajo aporte del sector empresarial a la política social y a la comunidad en general de la ciudad.

El análisis econométrico permite recomendar la necesidad de mejorar las posibilidades de acceso a medios de producción, transformación y comercialización, fomentar el desarrollo de los pequeños empresarios y brindar formas de apalancamiento que les permita acceder a emplazamientos adecuados, formalizarse, mantenerse en el tiempo y consolidarse como empresas con crecimiento y perspectivas competitivas.

Teniendo en cuenta el censo empresarial de Ipiales, las instituciones gremiales y de gobernabilidad, deberán contemplar como prioridad en sus planes de desarrollo y programas sectoriales, la identificación y el desarrollo de las cadenas productivas en el municipio, las cuales pueden ayudar a incrementar la productividad del municipio y por ende mejorar el empleo e ingreso de los trabajadores.

La investigación completa se constituye en el estudio de línea base a nivel empresarial y económico de la ciudad de Ipiales, este elemento hace que las conclusiones aquí contempladas deban ser tenidas en cuenta para la toma de política pública y privada en la región.

\section{REFERENCIAS}

CÁMARA DE COMERCIO IPIALES (2008). Informe del Movimiento del Registro Público. Departamento de Planeación y Estudios Económicos. p. 13.

CÁMARA DE COMERCIO DE BOGOTÁ (2010), Censo Empresarial de Soacha.

CÁMARA DE COMERCIO DE BOGOTÁ (2006). Censo Empresarial de Chapinero. Horizontes Gráficos.

PRESIDENCIA DE LA REPÚBLICA. Código de Comercio, decreto 410 de 1971. 